Derecho y Realidad

Núm. 22 • II semestre de 2013

Facultad de Derecho y Ciencias Sociales, UPTC

ISSN: 1692-3936

\title{
Fundamentos filosóficos, éticos, jurídicos $Y$ políticos para el estudio de la interrelación entre derechos humanos $y$ democracia
}

Philosophical, ethical, legal and political foundations for the study of the interrelationship between human rights and democracy

Pablo Guadarrama González

\section{Resumen}

La aproximación a los conflictivos y polisémicos significados de los conceptos de derechos humanos y democracia, desempeña un papel significativo en los puntos de referencia, perspectivas y objetivos del investigador en cuestión. Por lo tanto, una comprensión real y precisa de las funciones de la filosofía para facilitar el análisis de los derechos humanos y de la democracia, permite detenerse en la valoración del significado del componente ideológico y jurídico en el estudio de la interacción entre los mismos.

Si las filosofías renuncian a la intención utópico-concreta de intervenir activamente en el perfec-cionamiento de la conducta humana, como es el caso del estudio de los derechos humanos, en su posible nexo con la democracia, dejan de ser propiamente filosofias, como cuando se subordinan

\footnotetext{
* Académico titular de la Academia de Ciencias de Cuba, doctor en Ciencias (Cuba) y doctor en Filosofía (Alemania). Doctor Honoris Causa en Educación (Perú), doctor en Filosofía (Colombia). Profesor titular de la Cátedra de Pensamiento Latinoamericano de la Universidad Central de Las Villas, Santa Clara, Cuba.
} 
irreflexivamente a posturas políticas, ideológicas o jurídicas en lugar de propiciarlas racionalmente.

\section{Palabras clave}

derechos humanos, democracia, filosofía, epistemología, análisis, sociedad.

\section{Abstract}

The approach to the conflictive and polysemic meanings of the concepts of human rights and democracy plays a significant role in the benchmarks, perspectives and aims of the researcher in question. Therefore, a true and accurate understanding of the functions of philosophy to facilitate analysis of human rights and democracy, allows pausing in the assessment of the significance of ideological and legal component in the study of the interaction between them.

If the philosophies renounce the concrete utopian intention to intervene actively in the improvement of human behavior, such as the study of human rights in their possible link with democracy, they stop being philosophies, such as when they are thoughtlessly subordinated to political ideological or legal positions rather than promote them rationally.

\section{Key words}

human rights, democracy, philosophy, epistemology, analysis, society. 


\section{Introducción}

Desde las primeras etapas de la evolución de la sociedad, al hombre le han preocupado los temas relativos a la manera de organizarse para lograr una mejor convivencia en distintos tipos de comunidades, la cuestión del poder, las formas de gobierno, la violencia, sus deberes y derechos en las diferentes formas de organización política, aun cuando esto no significase que haya elaborado desde un inicio un cuerpo teórico sobre estos diversos problemas.

Su relación, especialmente con sus semejantes, le ha obligado a pensar en la existencia de formas de dominio y control sobre ellos, así como en la existencia o no de mediadores entre los mismos, bien como entidades supraterrenales o como personalidades que encarnaban fuerzas carismáticas y superiores a las personas comunes.

De esa forma, los análisis sobre los temas del poder y, posteriormente, de los tipos de gobernabilidad y Estado, diferentes formas de monarquías y repúblicas, así como el de los instrumentos jurídicos y políticos para salvaguardar las instituciones establecidas, los deberes y derechos de esclavos y amos, siervos y señores, ciudadanos y mandatarios, etc., se convirtieron paulatinamente en cuestiones de debates imprescindibles para explicar las facetas funda-mentales del desarrollo del proceso civilizatorio.

Especialmente en América Latina estos temas han adquirido una extraordinaria importancia para las ciencias sociales en los últimos años. Como asegura Nobert Lechner (1985, p. 57): "la democracia se había convertido en el tema central de las ciencias sociales suramericanas. "La dramática alteración de la vida cotidiana que se da como consecuencia del golpe de Estado y la pérdida de seguridad y consecuente incertidumbre, lleva a los intelectuales a una revalorización de la democracia formal a partir de su propia experiencia particular".

El hecho de que diccionarios y otras publicaciones recojan innumerables definiciones de los conceptos de derechos humanos, Estado, democracia, etc., constituye una expresión de que hombres de distintas latitudes y épocas han reflexionado y continúan haciéndolo sobre ellos, tomando en consideración como presupuesto la diversidad de criterios -incluso abiertamente contradictorios-, existentes al respecto.

Pero esto no debe en modo alguno estimular la complacencia que limite la formulación de nuevas definiciones y problemas sobre sus particularidades y nexos. Por tal motivo resultan al respecto algo preocupantes la idea de Humberto Maturana, según la cual no recomienda argumentar la necesidad la democracia y por tanto no defenderla. Según su criterio: "Depende de lo que queramos, pero si uno se 
descorazona, no hace nada. Una democracia es una obra de arte que se crea cotidianamente. No se puede defender, solamente se puede vivir; en el momento que usted la defienda genera una tiranía” (1995, p. 82). Ser consecuente con esta postura conllevaría no solo abandonar la producción teórica sobre la democracia, sino algo que resultaría peor: dejarnos arrastrar por la existencial vivencia cotidiana del arte de la democracia, sin saber a qué lugar esta actitud nos puede llevar, con muchas posibilidades que nos conduzca a regímenes profundamente antidemocráticos.

Por supuesto que todo dependerá mucho de lo que se entienda por derechos humanos y democracia. Pero aun así habrá que tomar conciencia de que cualquier clasificación de especialidades filosóficas, y subordinación jerárquica entre ellas, por justificada que sea desde la perspectiva docente o investigativa al delimitar sus objetos respectivos de estudio, de algún modo atentará siempre contra el carácter integrador y de concepción teórica generalizadora y racional del mundo que el hombre le ha reservado a la actividad filosófica desde su gestación y al análisis científico, especialmente, a partir de la modernidad.

En la aproximación a los conflictivos y polisémicos significados de los conceptos de derechos humanos y democracia, desempeñan un papel significativo los puntos de referencia, perspectivas y objetivos del investigador en cuestión.

Sabido es que el arraigo que han tenido en América Latina, especialmente desde las últimas décadas del pasado siglo $\mathrm{XX}$, -con el debilitamiento gradual de los anteriormente predominante regímenes totalitarios-, tales problemáticas sobre los derechos humanos y la democracia.

Es bien conocido que las dictaduras militares latinoamericanas trasladaron las conflictivas situaciones de crisis económicas a los gobiernos democráticos que les sucedieron, como plantea Peter Smith: "Las transiciones de los últimos años se dan en condiciones de crisis económica, los regímenes militares no fueron capaces de solucionar ni la crisis de la deuda, ni la crisis de la acumulación" (1992, p. $375)$.

El carácter polisémico de estos conceptos de derechos humanos y de democracia obliga, siempre que se analizan detenidamente, a establecer algunos parámetros definitorios que contribuyan al manejo posterior de sus derivaciones y empleos.

Estos temas encierran profundas controversias ideológicas, las cuales no son posible desatenderlas en modo alguno a la hora de enjuiciar el asunto, bien para asumirlas o bien para criticarlas. En verdad, como plantea Javier Muguerza que: "Nunca como en el presente parecen haber gozado los derechos humanos de un grado de 
reconocimiento jurídico comparable a la escala planetaria. Y semejante reconocimiento convierte esos derechos -por encima o por debajo de sus nada infrecuentes violaciones, allí donde alcanzan a regir, y de su generalizada falta de aplicación, allí donde solo rigen nominalmente-, algo así como en un hecho incontrovertible” (2006, p. 153).

Se requiere analizar, en primer lugar, algunos de los fundamentos conceptuales del Estado para poder enjuiciar debidamente la interacción entre derechos humanos y democracia. Se debe aspirar a que los cursantes logren una visión general de los fundamentales ejes teóricos y un adecuado manejo de los principales elementos conceptuales alrededor de los cuales se centra la interrelación entre estos dos conceptos para que puedan proceder a un análisis más efectivo de casos concretos.

Solamente un conocimiento preciso sobre el origen, desarrollo, naturaleza y principales expresiones de los conceptos de derechos humanos y de democracia. Permite facilitar las debidas inferencias lógicas de la mejor interconexión entre ellos.

Del mismo modo, una reflexión profunda sobre algunas de las principales posturas filosóficas que se han desarrollado en la historia de la humanidad, especialmente de la modernidad, y en particular en América Latina (Guadarrama, 2012) sobre los temas de contenido antropológico, ético, político y jurídico, hace posible analizar debidamente la conformación y defensa de los derechos humanos en su interacción la democracia.

Es imprescindible plantearse los ejes conceptuales preliminares para el análisis de algunas de las principales temas que se plantean la investigación sobre el nexo entre los derechos humanos y la democracia a partir de justipreciación de los antecedentes, origen, formulación y desarrollo de los nexos existentes entre estos dos elementos, fundamentalmente desde el Renacimiento, así como el reconocimiento universal de su validez y legalidad reconocida de los derechos del hombre y de la necesaria imbricación de estos con la sociedad civil y la sociedad política.

Constituye una necesidad insoslayable que los funcionarios públicos de diversas instancias y niveles conozcan con profundidad los fundamentos teóricos y conceptuales de la especificidad de cada uno de los términos de lo que comúnmente se concibe como derechos humanos y democracia. Pero más allá de un conocimiento teórico de los mismos, lo que se debe lograr es que desarrollen competencias y habilidades para operar debidamente con las correspondientes funciones de cada uno de ellos en beneficio de sus respectivos pueblos. 
Solamente una comprensión precisa de las funciones de la filosofía para facilitar el análisis de los derechos humanos y de la democracia, permite detenerse en la valoración del significado del componente ideológico y jurídico en el estudio de la interacción entre los mismos.

Del mismo modo es indispensable un manejo del concepto de humanismo, de las implicaciones teóricas y prácticas que implica un manejo adecuado de las exigencias que plantea tenerlo siempre presenta la máxima kantiana de tomar al hombre siempre como fin y nunca como medio en cuanto a la esencia del vínculo entre derechos humanos y democracia.

Para poder entender el estado actual del desarrollo de la interrelación entre derechos humanos y democracia, se requiere conocer los antecedentes históricos de estos conceptos, especialmente en el plano filosófico, ético, jurídico y político, pues de otro modo se dificulta comprender la especificidad de cada uno de ellos.

Se necesita una mejor comprensión del origen así como la evolución de derechos humanos y de la democracia durante la Antigüedad y el Medioevo que permitan valorar el proceso de maduración y delimitación de funciones que demanda la modernidad. Pero, al mismo tiempo, es necesario detenerse en la consideración de los derechos humanos y de democracia en pueblos al margen de la cultura occidental.

El eurocentrismo ha conducido erróneamente a pensar que solo los pueblos de Europa han sido capaces de desarrollar una praxis política y jurídica lo mismo que una teoría política y jurídica referida a estos cruciales temas. Sin embargo la vida ha demostrado que algunas de las consideraciones revalorativas del papel del Estado en su correlación con los derechos humanos y la democracia no proceden exclusivamente de la cultura occidental (Guadarrama, 2009, p. 79-96).

No cabe la menor duda de que la modernidad fue el factor catalizador básico en la conformación de los derechos humanos y de la democracia con desarrollo de los Estados nacionales, \% que el discurso postmoderno pretendió inútilmente situar en conflictiva crisis (Guadarrama, 2008, p. 59-73) \% en los que los gobiernos debían estar regidos por normas éticas y jurídicas bien definidas y reglamentadas.

Fue el pensamiento de la Ilustración el que mayor atención le pondría a la conceptualización del Estado, los derechos humanos y la democracia. Y en la actualidad, cuando ese pensamiento ha cristalizado en múltiples ideologías y filosofías, se ha hecho urgente y necesario replantearse las más usuales definiciones sobre los derechos humanos y la democracia, así como las características y funciones que deben cumplir hoy en día los Estados y gobiernos, y en especial sus fuerzas militares. 
Al mismo tiempo se hace necesario arribar a definiciones precisas de términos tan orgánicamente vinculados al tema de los derechos humanos como: democracia, totalitarismo, autoritarismo, militarismo, civilidad, etc., de manera que puedan ser fácilmente reconocibles y diferenciados.

Una forma de contribuir a que un funcionario público, pueda arribar a algunas conclusiones sobre la validez, protección y jerarquización de los derechos humanos es conociendo a cabalidad su clasificación y adecuada definición. Ignorar algunas de sus características o exigencias puede conllevar a propiciar violaciones inconscientes o por desconocimiento, las cuales no eximen de la comisión de delitos. Por tanto, constituye una misión de los Estados y gobiernos formar debidamente a sus funcionarios, empleados, soldados, policías, etc., en el conocimiento del contenido teórico del ejercicio de las diversas formas de democracia, que no puede reducirse a la vida política, así como de los derechos humanos y en las indicaciones prácticas correspondientes para que estos sean respetados.

\section{Funciones de la filosofía en el análisis de la interrelación entre los derechos humanos y la democracia}

Algunos podrán cuestionarse en qué medida resulta funcional un tipo de conocimiento tan genérico y abstracto como el filosófico para el estudio de los derechos humanos y la democracia.

Precisamente la mayor utilidad del análisis filosófico radica en que posibilita una orientación de actitudes desde una perspectiva teórica más amplia que las que pueden ofrecer otras formas del conocimiento humano, como el de la ciencia, y contribuir a la toma de decisiones prácticas en el plano ético, político y jurídico. Se debe tomar en consideración siempre aquella recomendación de Albert Einstein según la cual no hay nada más práctico que una buena teoría.

El hombre puede tomar en consideración también elementos muy distintos para en análisis de estos dos elementos: los derechos humanos y la democracia, por su nivel de generalización y abstracción a los empleados en la perspectiva filosófica, cuando efectúa su análisis desde una parcela distinta del saber como el de la ciencia o incluso desde el saber común o la conciencia cotidiana de los sectores populares.

La filosofía por sí misma tampoco puede lograr todo el conocimiento a que aspira el hombre. Para ello es necesario que se apoye en los resultados de las ciencias y en toda la experiencia humana sistematizada.

Desde sus orígenes, desde la Antigüedad hasta nuestros días, ha desempeñado la filosofía un conjunto de funciones (cosmovisiva, epistemológica, axiológica, 
humanista, etc., [Guadarrama, 1998, p. 109-139]), como instrumento lógico y metodológico de intento de explicación de la realidad, especialmente social y política, con el fin de transformarla y perfeccionarla, aunque no sierre en sentido democrático, si bien ese ha sido la tendencia en la modernidad.

Si la filosofía aspira verdaderamente a ser útil en el análisis y promoción de los derechos humanos y la democracia tiene que argumentar sus formulaciones sobre la más sólida base lógica que siempre revelará el contenido en última instancia concreto, especialmente en el plano político y jurídico, de las formulaciones teóricas más abstractas. Sólo si la abstracción se constituye en camino de tránsito necesario de lo concreto sensible a lo concreto pensado sobre nuevas bases teóricas, se justifica la empresa del filosofar.

En esta ardua labor, la filosofía puede demostrar su función práctica en el estudio de los derechos humanos en su articulación con la democracia no solo a través de las mediaciones necesarias del conocimiento científico sino de otras formas de la práctica social como la dirección política del Estado y la salvaguarda de su institucionalidad mediante los instrumentos jurídicos nacionales e internacionales pertinentes.

Durante la Conferencia Mundial de Derechos Humanos de Viena, en 1993, se argumentaba en el plano filosófico y jurídico la articulación indivisible que existe entre derechos humanos, democracia y desarrollo. Estos tres elementos se conjugan armónicamente cuando se plantean y logran de algún modo ante todo la paz y por tanto sobrevivencia de la humanidad, desafiada actualmente por el calentamiento global y las consecuencias del ecocidio universal del cual nadie más que algunos hombres específicos, y no el conjunto de la humanidad, son responsables.

La filosofía es ante todo instrumento que posibilita al hombre ejercer una función hegemónica, de dominio y control sobre el mundo natural y social, especialmente, en el estudio de los derechos humanos en su vínculo con el Estado, y la sociedad civil. En nada contradice esta función a la emancipatoria y desalienadora que también debe cumplir la filosofía en distintos planos, aunque no siempre lo logre y sólo quede, en ocasiones, como una encomiable intención.

Dondequiera que han germinado ideas de corte filosófico, estas indican que el hombre ha llegado a un grado de maduración teórica e intelectual que le posibilita abstracciones más acabadas sobre los constantes problemas objeto de su reflexión, como el referido al estudio de los derechos humanos en su interrelación con la democracia que constituye el objeto de este curso virtual.

La filosofía no ha tenido como única misión la satisfacción de tareas de exclusivo carácter teórico. Desde que este tipo de saber se constituye, porta en sí una función 
práctica-educativa, y de reconstrucción ética, política y jurídica de la sociedad, en función de determinados sectores sociales, clases, partidos, grupos, etc., aun cuando todas las apariencias indiquen lo contrario y sean frecuentes las declaraciones de representación de intereses universales de toda la sociedad.

Las filosofías son creaciones humanas cultivadas con intenciones, por supuesto, humanas, aun cuando los resultados no siempre, como en otras tantas ocasiones, no coincidan con aque-llas, como se revela en concepciones misantrópicas, nihilistas, fatalistas, enajenantes, de algunos pensadores, como Nietzsche o Cioran.

Incluso en aquellos casos en que los elementos misantrópicos han aflorado en mayor medida, no puede descartarse de antemano la presumida intención de comprensión de la naturaleza y la conducta humana que han servido de base a tales concepciones por sus implicaciones éticas y jurídicas.

Si las filosofías renuncian a la intención utópico-concreta de intervenir activamente en el perfeccionamiento de la conducta humana, como es el caso del estudio de los derechos humanos, en su posible nexo con la democracia, dejan de ser propiamente filosofías, como cuando se subordinan irreflexivamente a posturas políticas, ideológicas o jurídicas en lugar de propiciarlas racionalmente.

En ese sentido, la filosofía puede contribuir a darle una dimensión real a la utopía de la construcción de sociedades democráticas como plantea Fernando Ainsa: "Hablar de la necesidad de utopizar la democracia, en la misma medida que proponemos una democratización de la utopía. Se trata de fuerzas que deben ser indisociables -la utopía y la democracia- se reconcilien, creando espacios de resistencia a toda forma de dominación en la mejor tradición del racionalismo secular y crítico de raíz universitaria; se trata de abrir una intensa y desprejuiciada interlocución entre una utopía, desprendida de los tópicos totalitarios que le aquejan, y una democracia, capaz de radicalizar en profundidad los principios que la fundan" (2002, p. 35).

Las proyecciones ética, jurídica y política son también tan consustanciales a la filosofía como las demás funciones anteriormente esbozadas, siempre y cuando impere la racionalidad como indispensable instrumento argumentativo. Y esto se aprecia a lo largo de su historia a través de múltiples manifestaciones desde la Antigüedad hasta la modernidad, pero indudablemente en esta última es cuando el tema de los derechos humanos y del Estado democrático especialmente alcanza su plena madurez de estudio y pone de manifiesto todas las aristas ideológicas de su tratamiento. 


\section{El componente ideológico en el análisis de la interacción entre derechos humanos y democracia}

Las funciones axiológica, hegemónica, práctico-educativa, emancipatoria, utópica, ética, política y jurídica de la filosofía en su análisis de la interacción entre derechos humanos y democracia, quedan subsumidas en la función axiológica y articuladas a la función ideológica, si se entiende esta última no como especie de falsa conciencia o simple imagen pretenciosa de la realidad social, sino como conjunto de ideas que conforman la concepción de un gobierno, una clase, sector o grupo social, partido, iglesia, sindicato, organización no gubernamental, etc., y están dirigidas al sostenimiento o realización de su poder respecto a toda la sociedad o al menos a nombre de ellos.

Ninguna filosofía se puede reducir a que sea considerada exclusivamente como una ideología. Pero tampoco ninguna filosofía ha podido escapar a su función ideológica y mucho menos en el estudio de los derechos humanos en su vínculo con las instituciones y vías democráticas de poder.

Múltiples son los ejemplos que atestiguan desde la antigüedad que los filósofos, pensadores, profetas, etc., siempre han pensado y actuado sin desatender tales móviles ideológicos.

Toda filosofía ha aspirado a conformar una modelo social superior y especialmente las modernas a hacer todo lo posible para que se realice también una armónica interacción entre derechos humanos y formas democráticas de gobierno.

En ocasiones el fermento ideológico ha podido afectar el grado de objetividad de las consideraciones teóricas de los pensadores. Nadie ha podido escapar de aquellos impulsos que inducen a considerar el proyecto propio de restauración social y democrática con el mejor desempeño de los derechos humanos, como el mejor de todos los tiempos.

Por ejemplo reducir la democracia a su esfera política o jurídica, desatendiendo el necesario componente económico o social es una de las más acostumbradas formas de manipulación de la misma, del mismo modo que desvincularla del respeto a los derechos humanos. Al respecto, el premio nobel de paz, Adolfo Pérez Esquivel, se plantea: “¿Qué es la democracia? Muchas veces la confundimos con votar, poner el voto en una urna y decir que vivimos en democracia. Eso es simplemente el ejercicio de un hecho democrático, pero no es la democracia. Democracia significa derecho e igualdad para todos, no para algunos. Derechos humanos son valores indivisibles en la construcción democrática. También debemos construir la democracia” (1999, p. 52). 
Cuando la carga ideológica ha sido desproporcionada, el efecto de dicha función en el análisis teórico del nexo entre derechos humanos y la praxis democrática, lejos de favorecerlo lo ha entorpecido, tergiversado y en ocasiones hasta produce el efecto contrario al deseado por el filósofo-ideólogo.

Aquellos que han pretendido escapar al influjo de las ideologías y refugiarse en una esfera absolutamente desideologizada, por lo común, han producido un efecto opuesto al desarrollo de las distintas formas de democracia y se ha detectado fácilmente el doblez del disfraz.

Resulta mucho más loable y ético cuando los funcionarios públicos tienen plena conciencia de los intereses ideológicos que subyacen en las prácticas políticas y jurídicas en la defensa de los derechos humanos y la realización de formas históricoconcretas de democracia, las cuales siempre tendrán limitaciones, si bien se orientan hacia formas superiores de construcción democrática.

\section{El humanismo: eje sustancial del vínculo entre derechos humanos y democracia}

El humanismo, entendido en su formulación más amplia, ha encontrado innumerables definiciones. Usualmente se maneja en su expresión clásica histórica como ese movimiento cultural que se despliega en la época renacentista entre aquellos intelectuales, profundos admiradores de la cultura grecolatina, que intentaban rescatar la dignidad humana tan atrofiada por siglos de servidumbre y eurocentrismo. En tal caso se presenta como un nuevo tipo de fe en los valores humanos hechos para el hombre. Por lo que no se diferenciaría mucho de otro tipo de religiosidad, en tal sentido antropocéntrica, lo cual no deja de implicar algunos riesgos.

El humanismo no constituye una corriente filosófica o cultural homogénea. En verdad se caracteriza en lo fundamental por propuestas que sitúan al hombre como valor principal en todo lo existente y partir de esa consideración, subordina toda actividad a propiciarle mejores condiciones de vida material y espiritual, de manera tal que pueda desplegar sus potencialidades siempre limitadas históricamente como se revela en el caso de los derechos humanos.

La toma de conciencia de estas limitaciones no se constituyen en obstáculo insalvable, sino en pivote que moviliza los elementos para que el hombre siempre sea concebido como fin y nunca como medio como debe ser en lo referido a los derechos humanos.

Las propuestas humanistas están dirigidas a reafirmar al hombre en el mundo, a ofrecerle mayores grados de libertad y a debilitar todas las fuerzas que de algún modo puedan alienarlo. 
Todo poder supuesto a fuerzas aparentemente incontroladas por el hombre, que son expresión histórica de incapacidad de dominio relativo sobre sus condiciones de existencia y engendradas consciente o inconscientemente por el hombre, limitando sus grados de libertad, se inscriben en el complejo fenómeno de la enajenación y la violación de los derechos humanos o el desconocimiento de las prácticas democráticas constituyen unas de las formas más acostumbradas en el mundo contemporáneo.

La filosofía se ha ido construyendo en su historia universal como un permanente proceso de aportación parcial por parte de sus cultivadores de distintos instrumentos desalienadores, ante el Estado y la sociedad civil, que contribuyen en diferente grado a la consolidación del lugar del hombre, del individuo humano, de la persona en el mundo. Cuando han constatado los distintos peligros enajenantes, que en circunstancias diversas afloran en la vida humana, han aportado en la mayor parte de los casos las vías para superarlos.

No es menos cierto que no han faltado quienes se han limitado a constatar o a poner de manifiesto formas enajenantes, como la subordinación al poder, de los gobernantes, de las fuerzas ocultas de la naturaleza, la economía, la sociedad, etcétera, sin contribuir mucho a encontrar los mecanismos para evadirlos, porque han partido de la fatal consideración de que estos son consustanciales a la condición humana. Pero de haber prevalecido estos criterios fatalistas en la historia de la civilización, hoy difícilmente podrían las nuevas generaciones humanas enorgullecerse de los avances alcanzados en todos los órdenes de perfeccionamiento social en cuanto a los derechos humanos.

La elaboración de concepciones e instituciones por lograr una sociedad más justa, democrática y humana es ancestral en múltiples culturas desde sus primeras expresiones históricas. Stanislao Zuleta advertía en relación con los orígenes de la democracia ateniense que: "La democracia implica la aceptación de un cierto grado de angustia. Grecia, a pesar de ser una sociedad esclavista, tenía a su modo una democracia, y desde el punto de vista ideológico era una sociedad pluralista... Sin embargo la democracia griega, a pesar de ser funcional e importante, era supremamente limitada ya que estaba restringida a una parte minoritaria de la población" (Zuleta, 1995, p. 122).

Tanto en las culturas egipcia, china, india, persa y grecorromana hay innumerables testimonios de ideas humanistas, comunitarias y utopistas, que después proliferaron también durante la Edad Media con su necesaria tonalidad religiosa e irrumpieron con mayor fuerza a partir del Renacimiento y se acrecentaron en la misma medida en que el capitalismo evidenciaba su contradictoria naturaleza fueron apareciendo las ideas del socialismo utópico. 
Derecho y Realidad

¿Es imaginable suponer que todos los pueblos que emprendieron tarea de iniciar la construcción de sociedades más justas donde se respetaran los derechos de los trabajadores y los sectores populares; dirigidos por partidos, sindicatos, organizaciones e instituciones culturales, etc., al frente de los cuales siempre hubo hombres de talento y de humanas aspiraciones, fuesen unos aberrados mentales y no tuviesen razones suficientes justificadas para darse a esa tarea?

Siguiendo la lógica del discurso podríamos hacernos las mismas preguntas en relación con los que han puesto en práctica regímenes totalitarios, militaristas, racistas y fascistas en esta misma época. A lo que se podría argumentar que los hechos no justifican los derechos.

La historia de la humanidad parece estar condenada a sufrir permanentemente los desastres de proyectos y experimentos sociales basados en doctrinas, que siempre se las ingeniarán para asirse de los más sofisticados fundamentos como lo demuestra el reciente fracaso del neoliberalismo con la actual crisis financiera internacional que tuvo su mayor expresión con el derrumbe bancario de Wall Street.

El eclecticismo y el espiritualismo metafísico han permeado también en ocasiones las concepciones conservadoras de los derechos humanos, ya que a partir del criterio de que existe una esencia humana o unos valores absolutos se han encargado de mitificar la existencia de dichos derechos sin concebirlos en su circunstancialidad e historicidad. Estas ideas en ocasiones conducen a concepciones mesiánicas de algunos líderes políticos al llegar a plantear que sus respectivos gobiernos han sido elegidos por alguna divinidad para su misión terrenal y a atribuirle a determinadas fuerzas militares atributos de protección sobrenatural.

Las ideologías proliferan en el actual mundo globalizado de formas muy sutiles y en ocasiones se dificulta encontrar sus expresiones específicas en el análisis de determinados problemas y conflictos sociales, pero este no es el caso en lo referido a la democracia y los derechos humanos. Pues si existe algún terreno en que de inmediato puedan identificarse la diversidad de posturas ideológicas detrás de las formulaciones jurídicas y políticas, es precisamente en este de los derechos humanos y la democracia.

La cuestión de los fundamentos filosóficos, éticos, jurídicos y políticos para el estudio de la interrelación entre los derechos humanos y democracia, constituirá siempre un problema de permanente preocupación, pues la actuación de la sociedad política y la sociedad civil dependerá en gran medida de su adecuada comprensión y asunción práctica. 


\section{Referencias}

Ainsa, F. (2002). La impostergable utopización de la democracia. Utopía y praxis latinoamericana. Revista internacional de filosofía iberoamericana y teoría social, 35. Universidad del Zulia, Maracaibo.

Guadarrama, P. (1998). ¿Para qué filosofar? (Funciones de la filosofía). Revista de Filosofía, (30), 109-139. Centro de Estudios Filosóficos Adolfo García Díaz. Recuperado de http://www.filosofia.org/mon/cub/dt021.htm

Guadarrama, P. (2008, I semestre). Los derechos humanos ante el conflicto modernidad y posmodernidad. Nova et Vetera, 59-73. Escuela Superior de Administración Pública. Bogotá. Recuperado de http://biblioteca.filosofia.cu/ php/export.php? format $=$ htm\&id $=2555 \&$ view $=1$

Guadarrama, P. (2009, II semestre). Democracia y derechos humanos: ¿"Conquistas" exclusivas de la cultura occidental? Nova et Vetera, 79-96. Escuela Superior de Administración Pública, Bogotá. Recuperado de http:// www.espaciocritico.com/

Guadarrama, P. (2012). Pensamiento filosófico latinoamericano. Humanismo, método e historia. Tomo I y II. Bogotá: Planeta.

Lechner, N. (1985, mayo-agosto). De la revolución a la democracia. El debate intelectual en América del sur. Opciones, (6). Santiago de Chile.

Maturana, H. (1995). La democracia es una obra de arte. Bogotá: Mesa Redonda Magisterio.

Muguerza, J. (2006). La alternativa del disenso. En J. Muguerza. Fundamentación de los derechos humanos. (p. 153). Madrid: Debate.

Pérez, A. (1999). Los desafíos de la Paz y los derechos humanos en el Nuevo Milenio. En UNESCO-Universidad Federal de Paraná. Por una cultura de paz. (p. 52). Brasil: s.n.

Smith, P. H. (1992, octubre-diciembre). Crisis y democracia en América Latina. Desarrollo Económico: Revista de Ciencias Sociales, 31(123), 375. Buenos Aires.

Zuleta, S. (1995). Educación y democracia. Un campo de combate. Bogotá: Corporación Tercer Milenio. 